\title{
Phase-change memory functionality in gallium nanoparticles
}

\author{
Andrey. I. Denisyuk, Fredrik Jonsson and Nikolay I. Zheludev
}

Optoelectronics Research Centre, University of Southampton, SO17 1BJ, United Kingdom

\author{
www.nanophotonics.org.uk
}

We report that the structural phase of gallium nanoparticles can be switched by optical excitation and read via their cathodoluminescence (CL) when excited by a scanning electron beam. This opens a new paradigm in developing highdensity phase change optical memory elements.
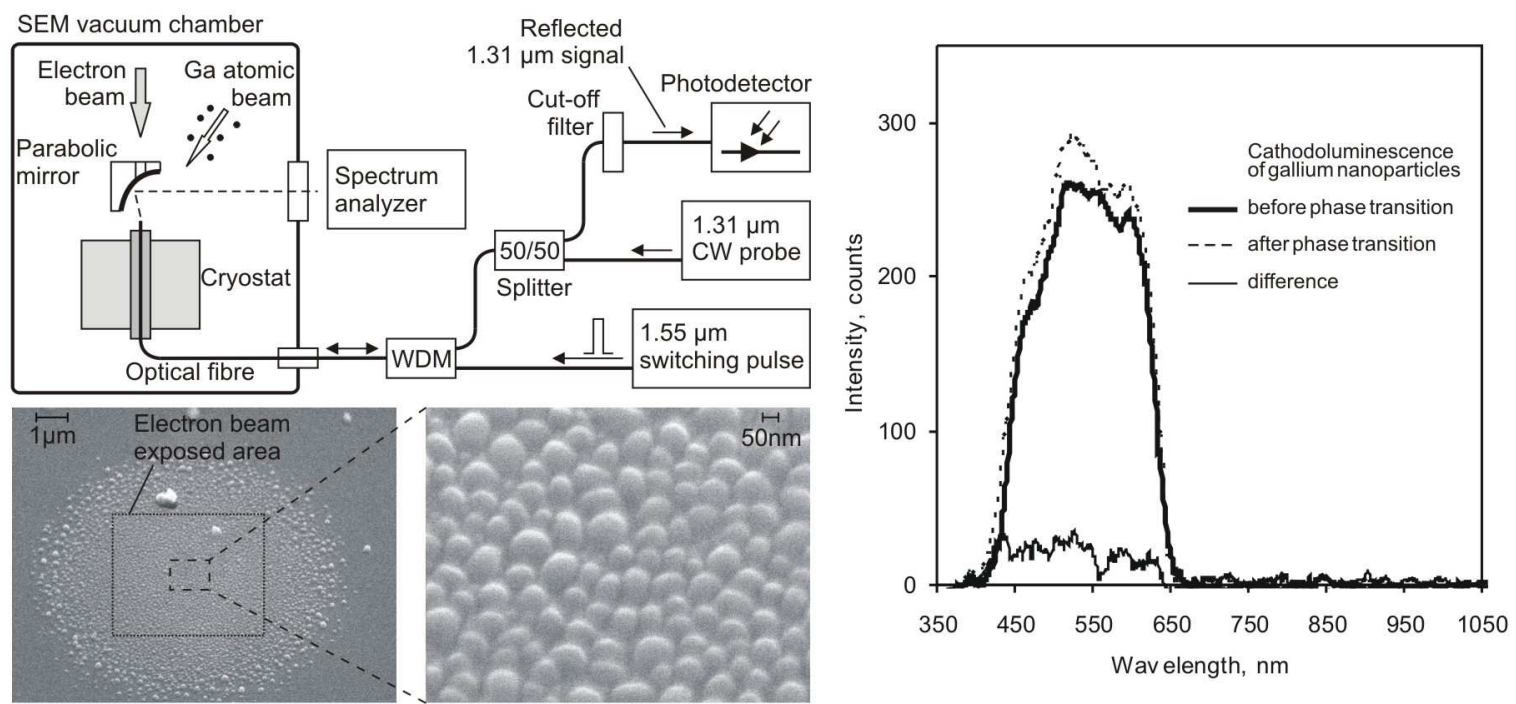

Figure 1. The experimental setup (left, top), the sample (left, bottom), and measured CL spectra (right).

A film of gallium nanoparticles was sputtered at the end face of an optical fiber, through which the reflectivity at $195 \mathrm{~K}$ was monitored by a $1.31 \mu \mathrm{m}$ laser (Fig. 1). By launching a single pulse from a $1.55 \mu \mathrm{m}$ laser $(17 \mathrm{~mW}, 1 \mu \mathrm{s})$ to the sample, a solid-to-liquid phase transition [1] was observed as an immediate change of reflectivity from 10.0 to $10.5 \%$. CL spectra were measured immediately before and after the phase transition. The spectra show that gallium nanoparticles luminesce in the range of $400-650 \mathrm{~nm}$, in which there at $520 \mathrm{~nm}$ is a $10 \%$ difference of emission before and after the phase transition, due to a difference in optical properties [2]. In future continuation of this first demonstration of electron beam read-out of the phase of nanoparticles, it is likely that the electron beam itself can change the phase of individual nanoparticles in the film, and that this phase furthermore can be read out at lower power by its cathode luminescence response with the same electron beam.

\section{References}

1. B. F. Soares, M. V. Bashevoy, F. Jonsson, K. F. MacDonald and N. I. Zheludev, Optics Express 14, 10652 (2006).

2. O. Hunderi and R. Ryberg, J. Phys. F: Metal Phys. 4, 2096 (1974). 